Marcum, C.D., Higgins, G.E., \& Ricketts, M.L. (2010). Potential factors of online victimization of youth: An examination of adolescent online behaviors utilizing Routine Activity Theory. Deviant Behavior, 31(5): $381-410$. Published by Taylor \& Francis (ISSN: 1521-0456). DOI:10.1080/01639620903004903

\title{
Potential Factors of Online Victimization of Youth: An Examination of Adolescent Online Behaviors Utilizing Routine Activity Theory
}

Catherine D. Marcum, George E. Higgins, \& Melissa L. Ricketts

\begin{abstract}
The purpose of this study was to investigate Internet usage in a sample of college undergraduates, as well as to consider their experiences with online victimization, through variables representing the three constructs of Routine Activity Theory. A survey was administered to 100-level courses at a mid-sized university in the northeast, which questioned respondents on their Internet behaviors and experiences with victimization during the high school senior and college freshman time period. The findings of the study indicated that participating in behaviors that increased exposure to motivated offenders and target suitability in turn increased the likelihood of the three types of victimization measured. Conversely, taking protective measures against victimization to improve capable guardianship did not decrease the likelihood of victimization. This research provides a significant contribution to the literature as there are few explanatory studies that attempt to identify causal reasoning for the victimization of adolescents online.
\end{abstract}




\section{INTRODUCTION}

According to Adler and Adler (2006), computer crime and victimization is on the rise. Several studies of Internet use by youth have found that increasing numbers of young people are experiencing the following types of victimization while using computer-mediated communication (CMC) methods: unwanted exposure to sexual material, sexual solicitation, and unwanted nonsexual harassment (Marcum forthcoming; Mitchell et al. 2003, 2007; O'Connell et al. 2002; Quayle and Taylor 2003; Sanger et al. 2004; Wolak et al. 2002, 2003, 2004, 2006, 2007; Ybarra et al. 2007). The majority of these studies are descriptive in nature, and therefore there is a lack of rigorous research that indicates what online behaviors may increase the likelihood of victimization.

Roncek and Maier (1991) suggested that Routine Activity Theory is excellent for use in the examination of predatory or exploitative crimes, the type of deviant behavior examined in this study. According to Routine Activity Theory, three elements must be present in order for a crime to occur: exposure to motivated offenders, a suitable target, and a lack of capable guardianship (Cohen and Felson 1979). This assertion has been supported in multiple studies of various types of criminal activity (Arnold et al. 2005; Gaetz 2004; Mustaine and Tewksbury 1999; Roncek and Bell 1981; Schreck and Fisher 2004; Spano and Nagy 2005; Tewksbury and Mustaine 2000), but studies utilizing Routine Activity Theory are lacking regarding the explanation of cyber crime and victimization, especially in the area of youth. The purpose of this study was to investigate the differences in online victimization between high school senior year and freshmen year of college using variables representing the three constructs of Routine Activity Theory.

\section{ADOLESCENT INTERNET USE AND VICTIMIZATION}

Multiple studies have recognized that increasing numbers of young people are experiencing the following types of victimization while using CMC methods: unwanted exposure to sexual material, sexual solicitation, and unwanted non-sexual harassment (Mitchell et al. 2003, 2007; O'Connell et al. 2002; Quayle and Taylor 2003; Sanger et al. 2004; Wolak et al. 2002, 2003, 2004, 2006, 2007; Ybarra et al. 2007), but few studies have attempted to explain why this is happening.

Of the few explanatory studies performed, those using data from the Youth Internet Safety Survey (respondents were between the ages of 10-17) found that use of chat rooms, discussion of sexual topics with online contacts, and a tumultuous relationship with family or friends increased the odds of online victimization (Mitchell et al. 2007; Wolak et al. 2007; Ybarra et al. 2007). Furthermore, using data from the high school senior and college freshmen time period, Marcum (forthcoming) found that increased exposure to motivated offenders and providing personal inn formation to online contacts also increased the likelihood of online victimization.

More recent empirical studies examined the effect of different forms of protective measures on adolescent online victimization. Fleming and colleagues (2006) and Marcum (forthcoming) 
found that the installation of filtering and blocking software had no affect on their exposure to inappropriate materials and behaviors and online victimization. Lwin and colleagues (2008) further explored protective measures through a quasi-experimental study of 10- to 17-year-olds in regard to their experiences with Internet monitoring and mediation by parents. They found that active Internet behavior monitoring by parents decreased the likelihood of participation in risky behaviors online, as well as exposure to inappropriate materials. However, Lwin et al. (2008) noted that the effectiveness of active monitoring decreased the older than adolescent became, which may be a foreshadowing of the results found in the current study considering the age of the sample.

There are few explanatory studies in the literature that attempt to assess the factors of online victimization; therefore, we do not have a complete understanding of why adolescents are victimized online. The literature is anemic in regard to studies that use a strong theoretical basis to examine these online outcomes including victimization. Routine Activity Theory would be useful in explaining this behavior.

\section{ROUTINE ACTIVITY THEORY}

Routine Activity Theory has shown itself to be useful in explaining different types of criminal victimization. Routine Activity Theory is somewhat similar to lifestyle/exposure theory (Messner and Tardiff 1985). According to Brantingham and Brantingham (1981), Cohen and Felson sought to expand and improve on the work of Hindelang et al. (1978) by incorporating ecological concepts, specifically Hawley's (1950) components of temporal organization: rhythm, tempo, and timing. Rhythm is the regularity with which events occur. Tempo is the number of events that occur per unit of time. Finally, timing is the duration and recurrence of the events. According to Cohen and Felson (1979), the inclusion of these three components improves the explanation of how and why criminal activity is performed.

Routine Activity Theory asserts that there are three components necessary in a situation in order for a crime to occur: a suitable target, a lack of a capable guardian, and a motivated offender (Cohen and Felson 1979). Moreover, crime is not a random occurrence, but rather, follows regular patterns that require these three components. According to Cohen and Felson (1979), target suitability is based on a person's availability as a victim, as well as his or her attractiveness to the offender. A person who is available for victimization is someone who has not taken certain precautions to protect themselves. Guardianship is the ability of persons and objects to prevent a crime from occurring (Cohen and Felson 1979; Garofalo and Clark 1992; Meier and Miethe 1993; Tseloni et al. 2004) and can take two forms: social and physical.

Finally, a motivated offender is a person who is willing to commit a crime when opportunities are presented through the presence and absence of the other two components (Cohen and Felson, 1979; Mustaine and Tewksbury 2002). In other words, the theory asserts that if a motivated offender is presented with a suitable target that is not properly guarded against victimization, a crime is likely to occur. 
Based on an examination of the relevant literature, Routine Activity Theory has been supported on both the macro- and micro-level. Although not as plentiful as micro-level research, macrolevel investigations of Routine Activity Theory have revealed empirical support for the components of the theory (LaGrange 1999; Pratt and Cullen 2005; Roncek and Bell 1981; Roncek and Maier 1991; Tseloni et al. 2004).

Micro-level studies utilize individual-level data, which allows for analysis of factors that specifically apply to individuals, rather than across large groups (Arnold et al. 2005; Cohen and Cantor 1980; Cohen and Felson 1981; Gaetz 2004; Mustaine and Tewksbury 1999; Spano and Nagy 2005; Tewksbury and Mustaine 2000).

Other tests Routine Activity Theory have indicated that persons at the college-age level, such as the respondents in this study, and females are likely to become victims of crime due to their routine activities. These studies support the utilization of the sample used in this particular study in order to further examine the usefulness of the theory in examining victimization during adolescence. For example, Jackson et al. (2006) examined prior and current deviance of male college students in relationship with athletic participation, fraternity participation, and opportunity. Analytic moment structures (AMOS) analysis indicated that college-level deviance was a significant indicator of sexually aggressive behavior. This behavior also was predicted by opportunity to commit the act. In other words, there is a higher likelihood an offender will be sexually aggressive if the opportunity to potentially commit the offense is present. Furthermore, Schwartz and colleagues (2001) investigated the likelihood of sexual assault on a college campus by applying Schwartz and Pitts' (1995) feminist model of Routine Activities Theory. Bivariate analysis revealed a significant relationship between sexual assault and level of alcohol and drug use for both men and women. Furthermore, a male with all three of these characteristics was almost 10 times as likely to commit an act of sexual aggression compared to a male with none of the characteristics (Schwartz et al. 2001).

Routine Activity Theory may provide a reasonable explanation of online victimization of youth. The more time that youth spend on the Internet, especially using social network sites, may increase their likelihood of being exposed to a motivated offender. The type of information that youth provide while using social network sites and their means of communication (i.e., chat rooms, instant messaging, or e-mail) may make them suitable targets for online victimization. The physical location, those in the location where the Internet is being used, and the knowledge level that parents have of the youths Internet use may be an indication of capable guardianship.

\section{THE PRESENT STUDY}

The purpose of the present study is to examine whether Routine Activity Theory may be able to help understand online victimization of youth. This study is important for a few reasons. First, to our knowledge, this is the first effort to attempt this sort of examination. Second, there is a general gap in the literature that attempts to explain online victimization of youth, especially utilizing a theoretical basis. Finally, by gaining a better understanding of this phenomenon, policies and programs can be developed to better protect adolescents during Internet use. 


\section{METHODS}

\section{Sample and Procedures}

After institutional review board approval, the data for the present study were collected during the spring 2008 semester. In order to obtain a representative sample of freshman, the lead author used all 100-level courses and respective sections at a mid-sized northeastern university as the sampling frame. From this list, 75 sections were randomly selected via the use of a random number table. Professors of these course sections were approached, and the data were collected from those course sections where the professors gave their permission. The students were informed that their participation was anonymous, confidential, voluntary, and that they had right to stop participating in the study if they wished to do so.

This set of procedures resulted in a total of 744 freshman students. Table 1 shows the sample has $55.8 \%$ females $(n=415)$ and $43.9 \%$ males $(n=325)$. The average age of the students was 19.3. The sample is $82.9 \%$ white $(n=613), 7.6 \%$ African American $(n=56)$, and $10.0 \%$ other $(n=70)$. At the time the data were collected, the freshmen population at the university from where the data are drawn from is $57.4 \%$ female $(n=1452)$ and $42.6 \%$ male $(n=1080)$. The average freshman age of the university is unknown. The freshman class at the university is $74.3 \%$ white $(n=1906), 14.5 \%$ African American $(n=371)$, and $11.2 \%$ other $(n=289)$.

TABLE 1 Characteristics of the Study Sample versus Freshman Population of the University $(n=744)$

\begin{tabular}{lcc}
\hline Variable & Sample demographics & Population demographics \\
\hline Sex & & \\
$\quad$ Male & 43.9 & 42.6 \\
Female & 55.8 & 57.4 \\
Race & & \\
White Non-Hispanic & 82.9 & 74.3 \\
African American & 7.6 & 14.5 \\
Other & 10.0 & 11.2 \\
\hline
\end{tabular}

\section{Measures}

The measures for the study include exposure to motivated offenders, target suitability, lack of capable guardianship, unwanted sexually explicit material, unwanted, non-sexual harassment, unwanted sexual solicitation, and control measures (i.e., sex, age, and race). See the Appendix for a complete listing of the frequencies and descriptive characteristics of all the variables. 


\section{Exposure to Motivated Offenders}

The measure of exposure to motivated offenders was operationalized in two sets of questions: general Internet use and types of activities. General Internet use was operationalized via the following two questions: "How many hours a day did/do you typically spend on the Internet?" and "How many days a week did/do you use the Internet?" Measurement of these questions was open-ended. Higher scores for these two questions indicated more general Internet use that increases the potential exposure to motivated offenders.

Types of activities were operationalized using the following set of questions: "Did/do you use email?" "If you answered yes, how many hours per week did/do you spend using email?" "Did/do you use instant messaging?" "If you answered yes, how many hours per week did/do you spend using instant messaging?" "Did/do you use chat rooms?" "If you answered yes, how many hours per week did/do you spend using chat rooms?" "Did/do you use social networking websites?" "If you answered yes, how many hours per week did/do you spend using social networking websites?" The hours per week spent using the various methods of CMC were used in the model to measure exposure. In order to produce a more normal distribution for these item and avoid a severe positive skew in the original variables, all extreme values in the tails were collapsed to create a recoded variable. This set of items addresses the issues that different activities may expose the student to motivated offenders.

\section{Target Suitability}

To capture target suitability (i.e., activities that make the student more attractive to motivated offenders), the students were asked to provide responses to the following series of questions: 'Was/is your social networking website marked 'private,' so only designated friends could/can see your profile?" "What types of information did/do you post on your social networking website?" Respondents were able to choose the following types of information: age, gender, descriptive characteristics, picture, telephone number, school information, extracurricular activities, goals, sexual information, emotional distresses, family conflicts, and other. Providing more types of information indicated a higher likelihood of being a suitable target. "Did/do you communicate with people online, via email, instant messaging, or chat rooms, that you had/have never met in person?" Dichotomous variables were created based on a no/yes response. "Did/do you voluntarily give personal information to a person you met online?" As for the previous measurement, dichotomous variables were created based on a no/yes response. "What types of information did/do you provide to an online contact?" Answer choices were the same types of information as could be provided on a social networking website.

\section{Lack of Capable Guardianship}

To capture the lack of capable guardianship (i.e., the amount of monitoring experienced by respondent as high school seniors and college freshmen at the university, as well as selfprotective measures), we used five items. The first item was: "Where did/do you most often use 
a computer?" The second item was "Please mark any of the parties listed that were/are typically in the same room with you when you used/use a computer?" Respondents were instructed to mark all that applied and analyzed separately in the model to see if having a particular party in the room affected the likelihood of victimization. Responses included: parent, friend, teacher/counselor, sibling, someone else, no one. The third item was "Please mark all of the restrictions you had/have from your parent/guardian while using the Internet?" Respondents were instructed to mark all that applied and analyzed separately in the model to see if having a particular restriction affected the likelihood of victimization. Responses included: time spent online, viewing of adult websites, use of CMCs, other, and no restrictions. The fourth item was "To your knowledge, did/do your parent/guardian or another adult actively monitor your Internet use by regularly checking the websites you visited?" Dichotomous variables were created based on a no/yes response. The fifth item was "To your knowledge, was/is any type of blocking or filtering software on the computer(s) you typically used/use to protect you from unwanted materials?" Dichotomous variables were created based on a no/yes response.

\section{Dependent Measures}

Three dependent measures were examined in this particular study. Respondents were asked if, during their high school senior year, they had received the following from a person online: sexually explicit material (e.g., pornography), non-sexual harassment (e.g., unwanted emails, instant messages), and sexual solicitation (e.g., request for either online or offline sexual interaction). Dichotomous variables were created based on a no/yes response.

\section{Control Measures}

Three measures were used as controls in this study. We controlled for sex $(0=$ female and $1=$ male). Students indicated their racial or ethnic group as ( $1=$ white, $2=$ African American, and $3=$ other). The students indicated their age with an open-ended item: "How old are you?"

\section{Analysis}

Data obtained through administration of the survey was analyzed in different manners through various techniques. Since the dependent variables initially were measured as a dichotomy, logistic regression models were used to assess relationships between the independent variables and the likelihood of victimization. [1] Due to the large number of independent variables measured in this study, stepwise logistic regression was utilized to determine the appropriate variables to assess in the models. [2] In multivariate analysis, some variables can have a statistically significant effect only when another variable is controlled, which is called a suppressor effect (Agresti and Finlay 1997). As a result, backward elimination was selected as the method of stepwise regression, whereby all possible variables are initially contained in the 
model, and there is less risk of ruling out variables involved in suppressor effects (Menard 2002).

Another step taken to enhance the discovery of potential relationships was to relax the $p<.05$ criterion for retention of variables in the models. Bendel and Afifi (1977) asserted that $p<.05$ is too low and further recommended that the criterion for retention in the stepwise model be set at .15 or .20, so important variables are not excluded. The criterion for retention of variables in this study was set at .20, to better reveal any possible statistically significant relationships.

Furthermore, linear probability models first were utilized to identify any possible problems with multicollinearity, through the use of tolerance statistics and variance inflation factors.

\section{RESULTS}

Table 2 presents the logistic regression estimates for the dependent variable "receipt of sexually explicit material" comparing the high school senior and college freshman time period. The high school senior time period model was shown to explain a range of $9.6 \%$ to $13.8 \%$ of the variation in the dependent variable. Respondents who shopped online (Shop) and those who used chat rooms one or more hours per week (Chat) were over $65 \%$ more likely to be victimized, and those who communicated with online contacts also were more likely to receive sexual material. Moreover, the presence of a parent in the room (ParlnRm) $(b=.380, p<.05)$ and a teacher in the room (TeachInRm) $(b=.569, p<.05)$ with the respondent during Internet use increased the likelihood a high school senior would receive sexually explicit material online. The temporal ordering of these relationships may be important to consider, as it is possible that when respondents received sexually explicit material, a guardian was placed in the room with the respondent to prevent further occurrences of the victimization. In this particular study, there was not opportunity for respondents to clarify the order of these events. 
TABLE 2 Logistic Regression Estimates for the Dependent Variable of Receipt of Sexually Explicit Material $(n=7,424)$

\begin{tabular}{|c|c|c|c|c|c|}
\hline \multirow[b]{2}{*}{ Variable } & \multicolumn{2}{|c|}{$\begin{array}{l}\text { High school senior } \\
\text { time period }\end{array}$} & \multirow[b]{2}{*}{ Variable } & \multicolumn{2}{|c|}{$\begin{array}{l}\text { College freshman } \\
\text { time period }\end{array}$} \\
\hline & $\mathrm{B}(\mathrm{SE})$ & $\operatorname{Exp}(B)$ & & $\mathrm{B}(\mathrm{SE})$ & $\operatorname{Exp}(B)$ \\
\hline E-mail & $.113(.060)$ & 1.120 & E-mail & $.144(.075)$ & 1.155 \\
\hline Chat & $.061(.021)$ & $1.063^{* *}$ & Design & $.463(.278)$ & 1.590 \\
\hline Design & $.420(.222)$ & 1.522 & Facebook & $-1.199(.372)$ & $.301^{* *}$ \\
\hline Shop & $.522(.189)$ & $1.685^{* *}$ & SNWInfo & $.165(.065)$ & $1.180^{*}$ \\
\hline Other & $.366(.258)$ & 1.442 & Comm & $.621(.240)$ & $1.862^{*}$ \\
\hline Comm & $.573(.183)$ & $1.774^{* *}$ & SchLab & $-2.037(1.171)$ & .130 \\
\hline OtherRm & $.437(.236)$ & 1.548 & FriendlnRm & $-.612(.246)$ & $.542^{*}$ \\
\hline ParlnRm & $.380(.183)$ & $1.463^{*}$ & TeachlnRm & $-.926(.694)$ & .396 \\
\hline TeachlnRm & $.569(.245)$ & $1.766^{*}$ & OthInRm & $1.348(.259)$ & $3.848^{* * *}$ \\
\hline RestrictTime & $.340(.223)$ & 1.405 & Constant & $-2.639(.430)$ & $.071^{* * *}$ \\
\hline Sex & $-.309(.180)$ & .734 & & & \\
\hline Race & $.122(.064)$ & 1.130 & & & \\
\hline Constant & $-2.407(.267)$ & $.090^{* * *}$ & & & \\
\hline -2 Log-likelihood & \multicolumn{2}{|c|}{786.558} & & \multicolumn{2}{|c|}{499.935} \\
\hline Model Chi-Square & \multicolumn{2}{|c|}{73.283} & & \multicolumn{2}{|c|}{$83.963^{* *}$} \\
\hline Cox and Snell $\mathrm{R}^{2}$ & \multicolumn{2}{|c|}{.096} & & \multicolumn{2}{|c|}{.109} \\
\hline Nagelkerke $\mathrm{R}^{2}$ & \multicolumn{2}{|l|}{.138} & & \multicolumn{2}{|l|}{.197} \\
\hline
\end{tabular}

${ }^{*} p<.05 ;{ }^{* *} p<.01 ;{ }^{* * *} p<.001$.

Conversely, in regard to the college freshman time period, the full model was shown to explain $10.9 \%$ to $19.7 \%$ of the variation in the dependent variable. Having a person designated as "Other" in the room during Internet use (OthInRm) increased the likelihood of receipt of sexually explicit material by almost four times. The relationship of this person to the respondent will be discussed in detail later. Providing personal information on a social networking website (SNWInfo) also increased the likelihood of victimization $(b=.165, p<.05)$. Conversely, use of Facebook $(b=-1.199, p<.01)$ and having a friend in the room during Internet use (FrilnRm) $(b=-.612, p<.05)$ decreased the likelihood of receiving the material.

Table 3 presents the logistic regression estimates of for the dependent variable "receipt of nonsexual harassment" during the high school senior and college freshmen time period. The variables retained at the .20 level were shown to explain $10.7 \%$ to $14.7 \%$ of the variation in the dependent variable during the high school senior time period model. Socializing online (Social) $(b=1.094, p<.01)$ and providing various types of personal information to online contacts (ProvidedInfo) $(b=.122, p<.001)$ were statistically significant predictors of receipt of nonsexual harassment while online. Furthermore, having no one in the room with the respondent during Internet use (NoOneRm) increased the likelihood of victimization ( $b=.565, p<.05)$. On the other hand, respondents who used the Internet in a location with increased guardianship, 
such as the living room of their home (LivRm) $(b=-1.092, p<.05)$ or the school computer lab $($ SchLab) $(b=-1.819, p<.05)$ were less likely to be victimized in this manner online.

TABLE 3 Logistic Regression Estimates for the Dependent Variable of Receipt of Non-Sexual Harassment $(n=744)$

\begin{tabular}{|c|c|c|c|c|c|}
\hline \multirow[b]{2}{*}{ Variable } & \multicolumn{2}{|c|}{$\begin{array}{l}\text { High school senior } \\
\text { time period }\end{array}$} & \multirow[b]{2}{*}{ Variable } & \multicolumn{2}{|c|}{$\begin{array}{l}\text { College freshman } \\
\text { time period }\end{array}$} \\
\hline & $\mathrm{B}(\mathrm{SE})$ & $\operatorname{Exp}(B)$ & & $\mathrm{B}(\mathrm{SE})$ & $\operatorname{Exp}(B)$ \\
\hline IM & $.025(.015)$ & 1.025 & IntPerWk & $-.032(.014)$ & $.969^{*}$ \\
\hline Chat & $.043(.021)$ & $1.044^{*}$ & E-mail & $.136(.076)$ & 1.146 \\
\hline Research & $.784(.476)$ & 2.191 & IM & $.052(.032)$ & 1.054 \\
\hline Shop & $.290(.175)$ & 1.337 & Travel & $.319(.229)$ & 1.376 \\
\hline Social & $1.094(.371)$ & $2.981^{* *}$ & Shop & $.472(.263)$ & 1.603 \\
\hline Info & $.122(.033)$ & $1.130^{* * *}$ & OtherSNW & $1.052(.477)$ & $2.863^{*}$ \\
\hline LivRm & $-1.092(.487)$ & $.336^{*}$ & SNWInfo & $.127(.060)$ & 1.135 \\
\hline YourBed & $-1.151(.494)$ & .316 & Comm & $.636(.216)$ & $1.847^{k-k}$ \\
\hline OtherRm & $-.692(.504)$ & .500 & Dorm & $.769(.367)$ & $2.157^{*}$ \\
\hline SchLab & $-1.819(.794)$ & $.162^{*}$ & OtherPI & $1.631(.891)$ & 5.109 \\
\hline FriHome & $-1.984(1.172)$ & .143 & OthlnRm & $-.420(.305)$ & .567 \\
\hline OthPI & $-1.340(.092)$ & .262 & Sex & $.754(.234)$ & $2.135^{* *}$ \\
\hline SiblnRm & $.307(.192)$ & 1.360 & Age & $.186(.060)$ & $1.204^{* *}$ \\
\hline OthlnRm & $.427(.255)$ & 1.533 & Race & $.116(.079)$ & 1.123 \\
\hline NoOneRm & $.565(.190)$ & $1.760^{* *}$ & Constant & $-7.912(1.389)$ & $.000^{* * *}$ \\
\hline RestrictAdult & $-.326(.184)$ & .722 & & & \\
\hline RestrictCMC & $.890(.384)$ & $2.436^{*}$ & & & \\
\hline Constant & $-2.270(.718)$ & $.103^{* *}$ & & & \\
\hline -2 Log-likelihood & \multicolumn{2}{|c|}{878.591} & & \multicolumn{2}{|c|}{563.725} \\
\hline Model Chi-Square & \multicolumn{2}{|c|}{$83.819^{* * *}$} & & \multicolumn{2}{|c|}{$82.510^{* * *}$} \\
\hline Cox and Snell $\mathrm{R}^{2}$ & \multicolumn{2}{|c|}{.107} & & \multicolumn{2}{|c|}{.107} \\
\hline Nagelkerke $\mathrm{R}^{2}$ & \multicolumn{2}{|l|}{.147} & & \multicolumn{2}{|l|}{.182} \\
\hline
\end{tabular}

With regard to the model examining the college freshman time period, variables retained at the .20 level were shown to explain $10.7 \%$ to $18.2 \%$ of the variation in the dependent variable.

Multiple variables were revealed as significant predictors, especially those designated as control variables. Communicating with people online (Comm) $(b=.636, p<.01)$, as well as main use of the Internet in a dorm room (Dorm) $(b=.769, p<.05)$, increased the likelihood of receipt of nonsexual harassment online. With regard to gender, females were shown to be over 2 times more likely to receive non-sexual harassment $[\operatorname{Exp}(B)=2.135]$. Moreover, older respondents (Age) were more than $20 \%$ more likely to be victimized in this manner compared to the younger respondents $[\operatorname{Exp}(B)=1.204]$. 
Finally, the full logistic regression model examining the last type of victimization analyzed in this study, receipt of sexual solicitation, is presented in Table 4. Variables retained at the .20 level were shown to explain $9.7 \%$ to $18.0 \%$ of the variation in the dependent variable during the high school senior time period. Three independent variables were statistically significant predictors. Providing personal information to online contacts (ProvidedInfo) had the most highly significant impact on this type of victimization, as it increased the likelihood of receipt of sexual solicitation by approximately $20 \%[\operatorname{Exp}(B)=1.208]$ for each type of information provided. Main use of the Internet in locations noted as "Other Place" (OtherPl) (i.e., not in the parent's or friend's home, or school computer lab) also significantly increased this likelihood ( $b=1.803, p<.05)$. Lastly, increased use of chat rooms (Chat) increased the likelihood of receipt of sexual solicitation $(\mathrm{b}=.075, p<.01)$.

TABLE 4 Logistic Regression Estimates for the Dependent Variable of Receipt of Sexual Solicitation $(n=744)$

\begin{tabular}{|c|c|c|c|c|c|}
\hline \multirow[b]{2}{*}{ Variable } & \multicolumn{2}{|c|}{$\begin{array}{l}\text { High school senior } \\
\text { time period }\end{array}$} & \multirow[b]{2}{*}{ Variable } & \multicolumn{2}{|c|}{$\begin{array}{l}\text { College freshman } \\
\text { time period }\end{array}$} \\
\hline & $\mathrm{B}(\mathrm{SE})$ & $\operatorname{Exp}(B)$ & & $\mathrm{B}(\mathrm{SE})$ & $\operatorname{Exp}(B)$ \\
\hline Chat & $.075(.022)$ & $1.078^{* *}$ & IntPerWk & $-.031(.021)$ & .969 \\
\hline Social & $1.453(.753)$ & 4.573 & E-mail & $.247(.105)$ & $1.280^{*}$ \\
\hline Comm & $.450(.292)$ & 1.538 & IM & $.099(.045)$ & $1.104^{*}$ \\
\hline Info & $.185(.042)$ & $1.203^{* * *}$ & Chat & $.554(.286)$ & 1.470 \\
\hline OthPI & $1.830(.758)$ & $6.201^{*}$ & Facebook & $-.780(.414)$ & .458 \\
\hline FrilnRm & $.370(.240)$ & 1.447 & Comm & $1.141(.348)$ & $3.129^{* *}$ \\
\hline Sex & $.404(.275)$ & 1.498 & OthlnRm & $.929(.344)$ & $2.532^{* *}$ \\
\hline Constant & $-4.499(.780)$ & .011 & Constant & $-4.040(.678)$ & $.018^{* * *}$ \\
\hline -2 Log-likelihood & \multicolumn{2}{|c|}{490.091} & & \multicolumn{2}{|c|}{310.613} \\
\hline Model Chi-Square & \multicolumn{2}{|c|}{$74.254^{* * * *}$} & & \multicolumn{2}{|c|}{$43.592^{* * * *}$} \\
\hline Cox and Snell $\mathrm{R}^{2}$ & \multicolumn{2}{|c|}{.097} & & \multicolumn{2}{|c|}{.058} \\
\hline Nagelkerke $\mathrm{R}^{2}$ & \multicolumn{2}{|c|}{.180} & & \multicolumn{2}{|l|}{.151} \\
\hline
\end{tabular}

${ }^{*} p<.05 ;{ }^{* *} p<.01 ;{ }^{* * *} p<.001$.

In the college freshman model, variables retained at the .20 level were shown to explain $5.8 \%$ to $15.1 \%$ of the variation in the dependent variable. Multiple variables emerged as significant predictors of receipt of sexual solicitation. Both communicating with others online (Comm) ( $b=1.141, p<.01)$ and having a person designated as "Other" in the room during Internet use (OthlnRm) $(b=.929, p<.01)$ remained significant positive predictors. Moreover, increased use of e-mail $(b=.247, p<.05)$ and instant messaging $(\mathrm{IM})(b=.099, p<.05)$ increased the likelihood of this type of victimization. 


\section{DISCUSSION}

Today's adolescents grew up using the Internet, and in turn they are extremely familiar with the multiple opportunities of use available online. Youth are especially involved in online socialization with various methods of computer-mediated communication (CMC), such as email, chat rooms, instant messaging, and social networking websites. Moreover, not only are more adolescents using the Internet to socialize, they are also spending more time online (Izenberg and Lieberman 1998; Nie and Erbring 2000; United States Department of Commerce 2002). Unfortunately, while the use of CMCs can produce positive interaction and develop enjoyable relationships for its users, these young people spending extensive amounts of time online are also placing themselves at risk for an increased likelihood of victimization.

Examination of the data showed that behaviors that increased exposure to motivated offenders had a sizeable impact on the likelihood of victimization. Consistent with the findings of Marcum (forthcoming) and Wolak et al. (2007), respondents in this study reported that participation in certain activities while online, and amplified used of CMCs, increased the likelihood of victimization at both the high school senior and college freshman time period. The increased use of chat rooms was shown to be a significant predictor of victimization in high school seniors. These results, which indicated that exposure to motivated offenders increased a person's likelihood to experience victimization, are also consistent with previous victimization research using Routine Activity Theory. For example, Roncek and Maier (1991) found that increasing the number of cocktail lounges and taverns on a residential block increased the likelihood of crime in a particular area. Furthermore, Tewksbury and Mustaine (2000) found that persons who leave their property unsupervised for longer periods of time, exposing it potential offenders, were more likely to be victimized.

The examination of the data also showed that behaviors that increased target suitability had a large impact on the likelihood of victimization. In fact, participating in behaviors that increased target suitability was shown to have the largest affect on dependent variables during both the high school senior and college freshman time period. Supporting findings by Mitchell et al. (2007), this study indicated that communicating with people online and providing personal information to online contacts increased the likelihood of all three types of victimization measured in the study for respondents during the high school senior time period. Specifically in regard to the college freshman time period, respondents who participated in these same behaviors were also more likely to receive non-sexual harassment.

These findings were analogous with previous studies examining victimization through Routine Activity Theory. Multiple studies have found that decreasing a person's target suitability in turn decreases his or her likelihood of becoming a victim of crime (Felson 1986; Horney et al. 1995; Schreck and Fisher 2004). For example, Arnold et al. (2005) discovered that if the main activities of respondent involve drinking and other leisure activities, their level of target suitability is increased and in turn, they are more likely to be a victim of crime. Moreover, Wang (2002), during his examination of causal factors associated with bank robberies, determined that banks who presented themselves as suitable targets (i.e., excessive amounts of cash and located close to a major highway) were more likely to be robbed. 
Unlike the other two constructs of Routine Activity Theory, protective measures taken during Internet use (measured under the theoretical construct of lack of capable guardianship) had somewhat of an effect on the dependent variables measured in the study. In regard to measures examining lack of capable guardianship, findings from this study indicated that protective software had no significant effect on victimization for survey respondents. However, the monitoring presence of another person in the room during Internet use was shown to have significant effects on both high school seniors and college freshmen. This presence decreased the likelihood of receipt of sexual material and non-sexual harassment for college freshmen, but increased the likelihood of these same types of victimization for the high school senior. As noted before, an issue of temporal ordering may be present as a monitor may have been implemented during the use of the respondent after the incident of victimization.

An interesting note in regard to having a person designated as "Other" in the room during Internet use. During both the high school senior and college freshmen time periods, a few of the dependent variables measured were affected by the presence of this person designated as "Other." For example, college freshmen who had this person in the room were more likely to receive sexually explicit material and sexual solicitation. On the survey, the options of persons present in the room during Internet use included parents, friends, siblings, and teachers; however, there was no opportunity on the survey to provide a qualitative answer indicating who fell in the "Other" category. It could be assumed the "Other" category would include boyfriends/girlfriends and strangers, which would be consistent with the findings. The authors assume that if the respondent was referring to strangers present in the room during the respondents' Internet use, this would explain the increased likelihood of victimization for college freshman. Strangers would have no personal ties or vested interest in the respondent, and would in turn not be carefully monitoring their Internet use for fear of this victimization.

Alternatively, the presence of a boyfriend in the room during Internet use would prevent a female high school senior to arrange offline contact with a person met online, as the boyfriend has a vested interest in her safety. However, this assertion is purely speculation and would require adding this particular clarification to a future study.

The findings of this study indicated that respondents who spent an increased amount of time using the Internet and specific CMCs (in turn exposing their likelihood of encountering a motivated offender) were more likely to be victimized. Nevertheless, it would be futile to attempt to develop prevention programs that encouraged youth to reduce their use of the Internet. Use of the Internet is often necessary for educational purposes, and many youth use the Internet to socialize and connect with others. In fact, after the administration of the first Youth Internet Safety Survey, Wolak et al. (2002) determined that over half of the youth (55\%) examined reported the use of chat rooms, instant messages, and e-mail to communicate with people they had never met, with the hopes of forming relationships. Rather than encouraging youth to stop socializing on the Internet, it would be more effective to educate youth on the dangers present online so they are aware of the potential for victimization.

Adolescents using the Internet should be educated to only participate in online communication with people they know and trust. Many of the respondents in this study reported that they communicated with and provided personal information to people they met online, as well as 
participated in offline relationships with these online contacts. In other words, these youth were revealing personal information to complete strangers (people who may intend to prey upon a vulnerable population) and were likely to continue the virtual relationship offline through various modes of communication, often in person. Although none of the respondents in this study reported participating in unwilling sexual relationships with people met online, past research has shown that there are adolescents who are physically victimized by contacts met online (Kendall 1998; Tarbox 2000). If youth limit online communication to people they know, the risk of offline victimization should be lower.

\section{CONCLUSIONS}

With limited past research available, this study sought to generate greater understanding about the relationships between Internet behaviors and activities (representing the three constructs of Routine Activity Theory) and online victimization and relationship formation. Providing personal information to online contacts and communicating with people met online (variables representing the theoretical construct of target suitability) were the strongest and most consistent predictors of online victimization, as well as the formation of relationships with people met online. Moreover, use of certain CMCs (variables representing the theoretical construct of exposure to motivated offenders) also was shown to predict certain types of victimization. However, variables representing the third construct of Routine Activity Theory, lack of capable guardianship, were not shown to be strong or consistent predictors of online victimization of youth.

From the knowledge gained through this study, hopefully more effective policies and programs can be developed to educate youth and families about protecting themselves while online. Youth should be aware of who they are conversing with online and refrain from providing any type of personal information to people they do not know and trust. Although this study did not indicate that the use of protective practices decrease the likelihood of victimization, more active monitoring of adolescents (particularly younger ones) might allow parents and guardians to be proactive in preventing victimization.

Finally, there is ample opportunity for future research in this area. Surveying a wider age range of adolescents, as well as those in different geographical areas, would add to the knowledge base. Also, further investigation of the use of social networking websites and the offending behaviors of adolescents, as well as their familiarity with deceptive Internet practices, will advance our knowledge of the online behaviors and experiences of adolescents. With this knowledge, better protective measures and policies can be developed to keep adolescents safe online. 


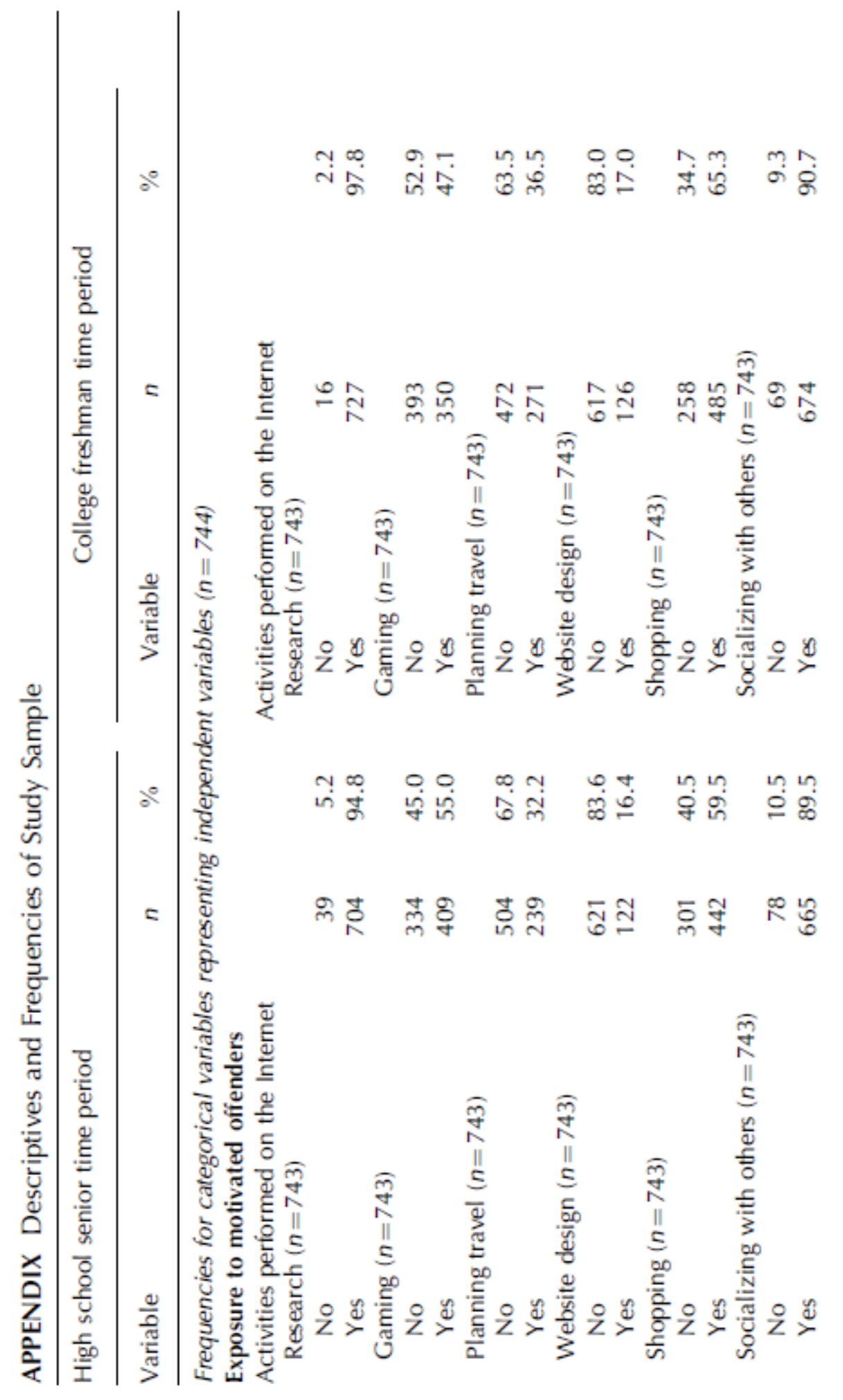




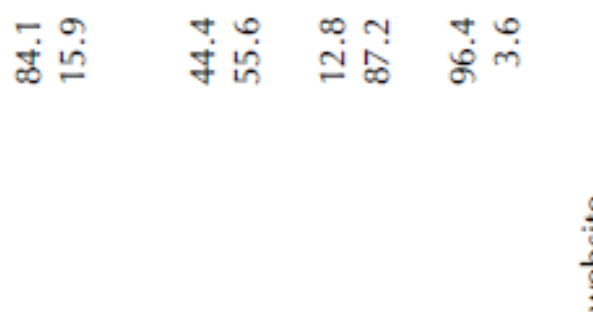

$\mid$

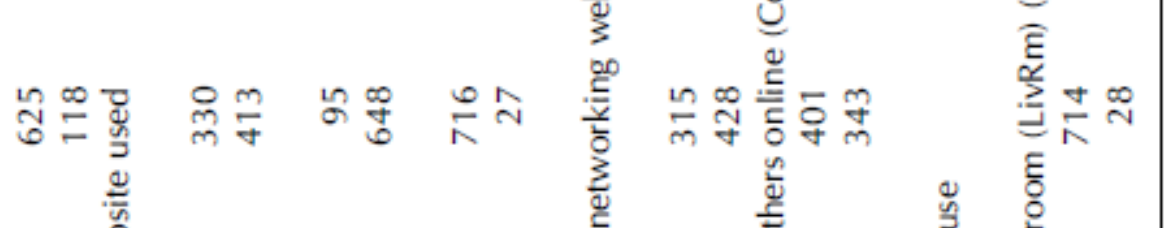

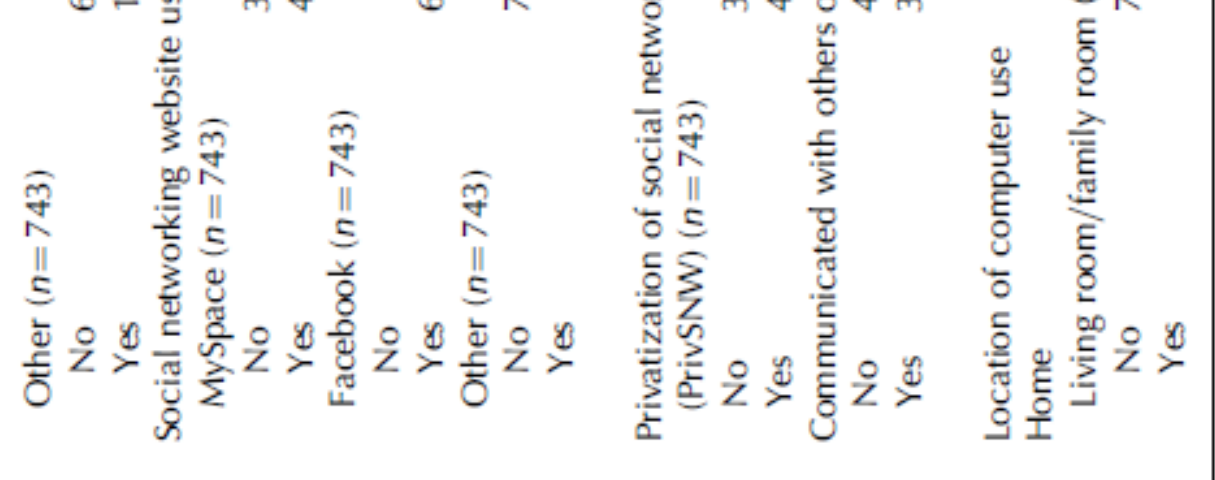

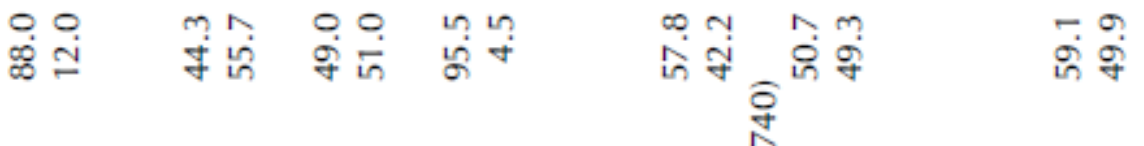

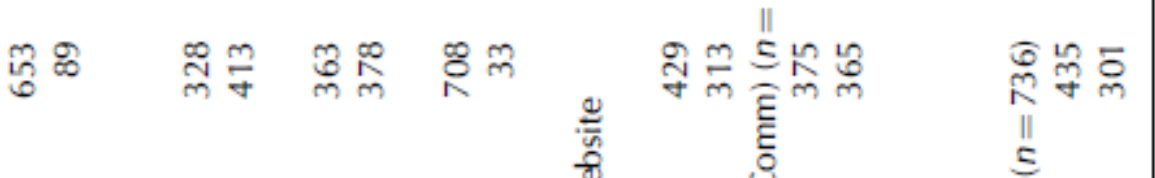

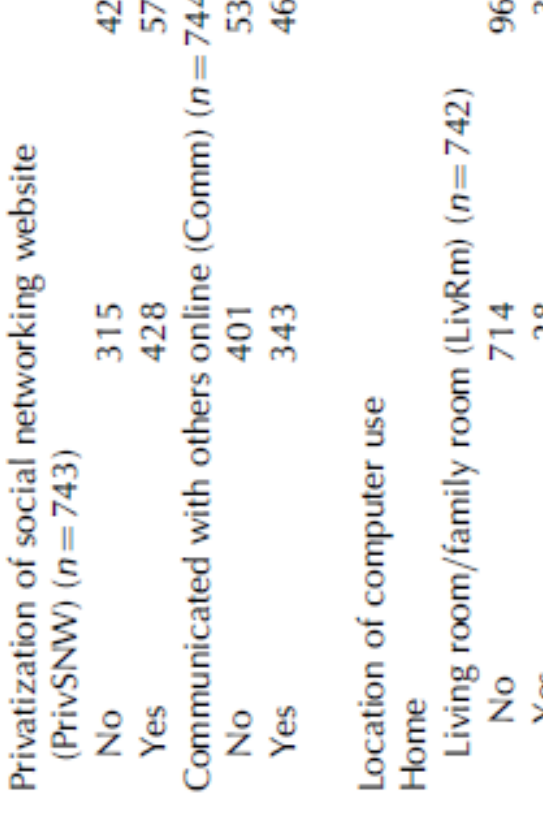




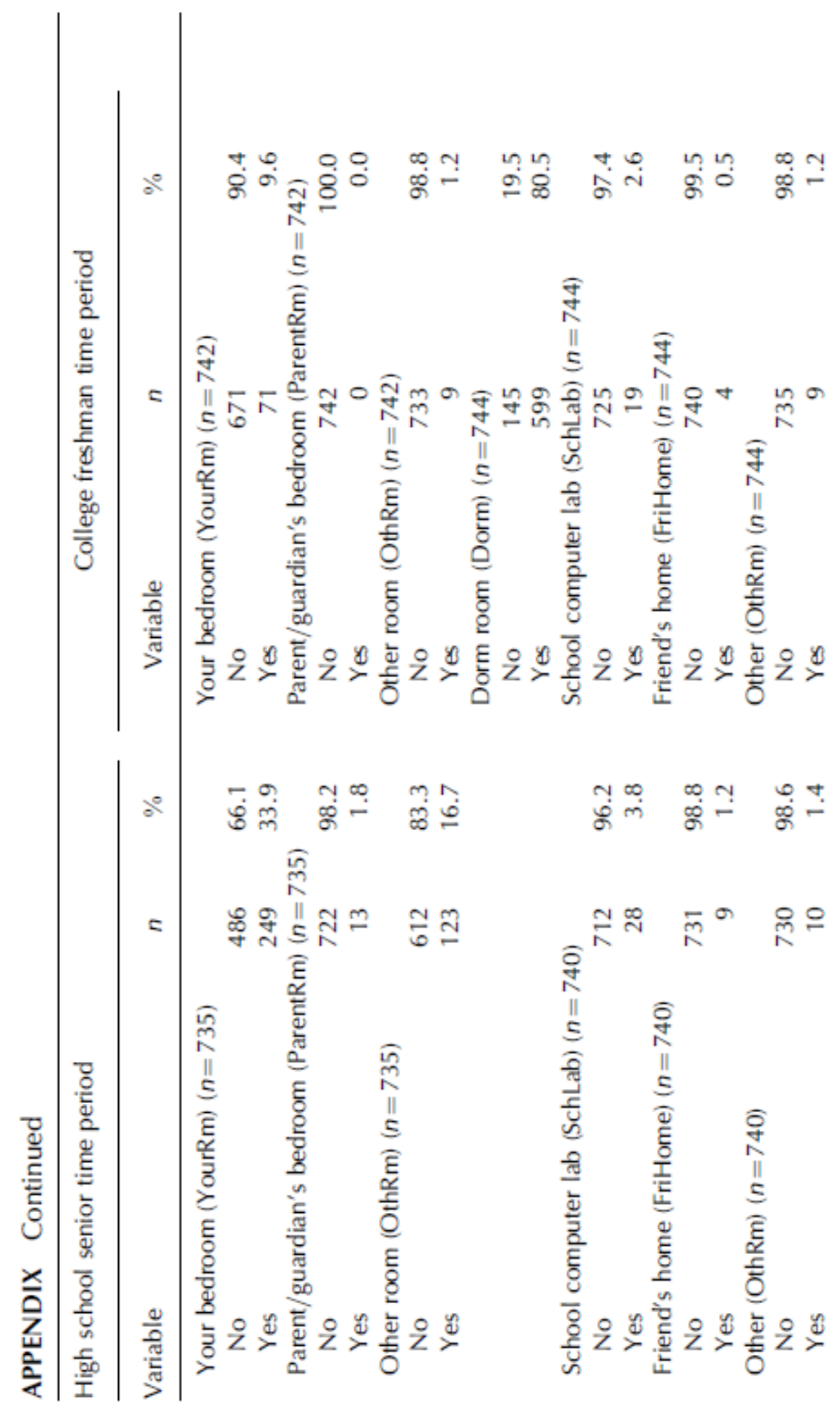




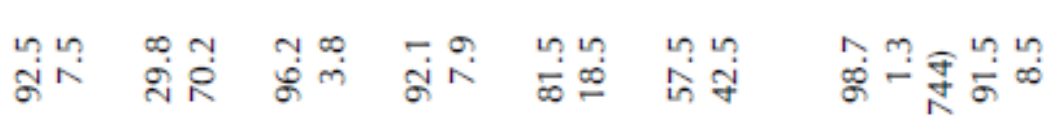

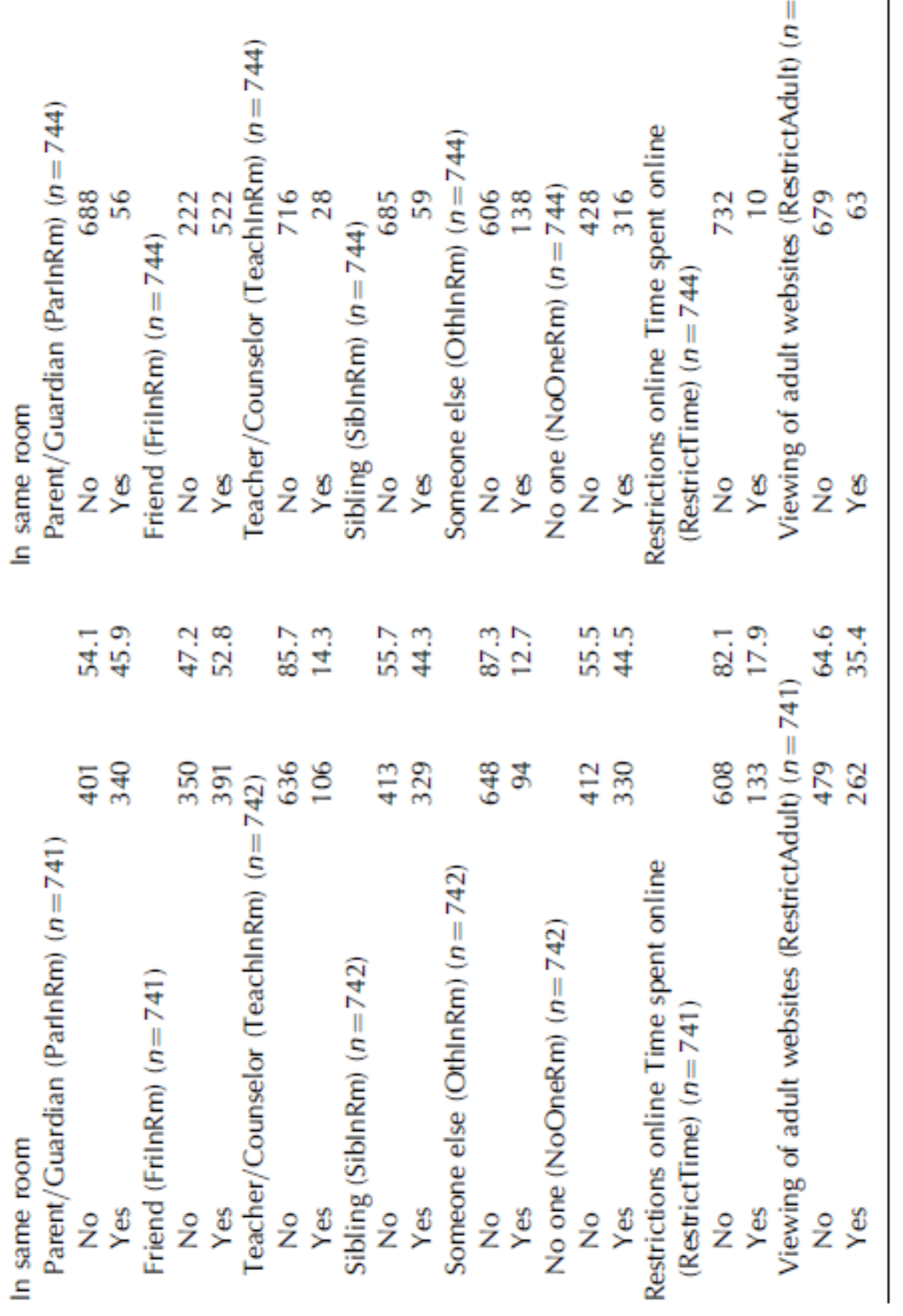




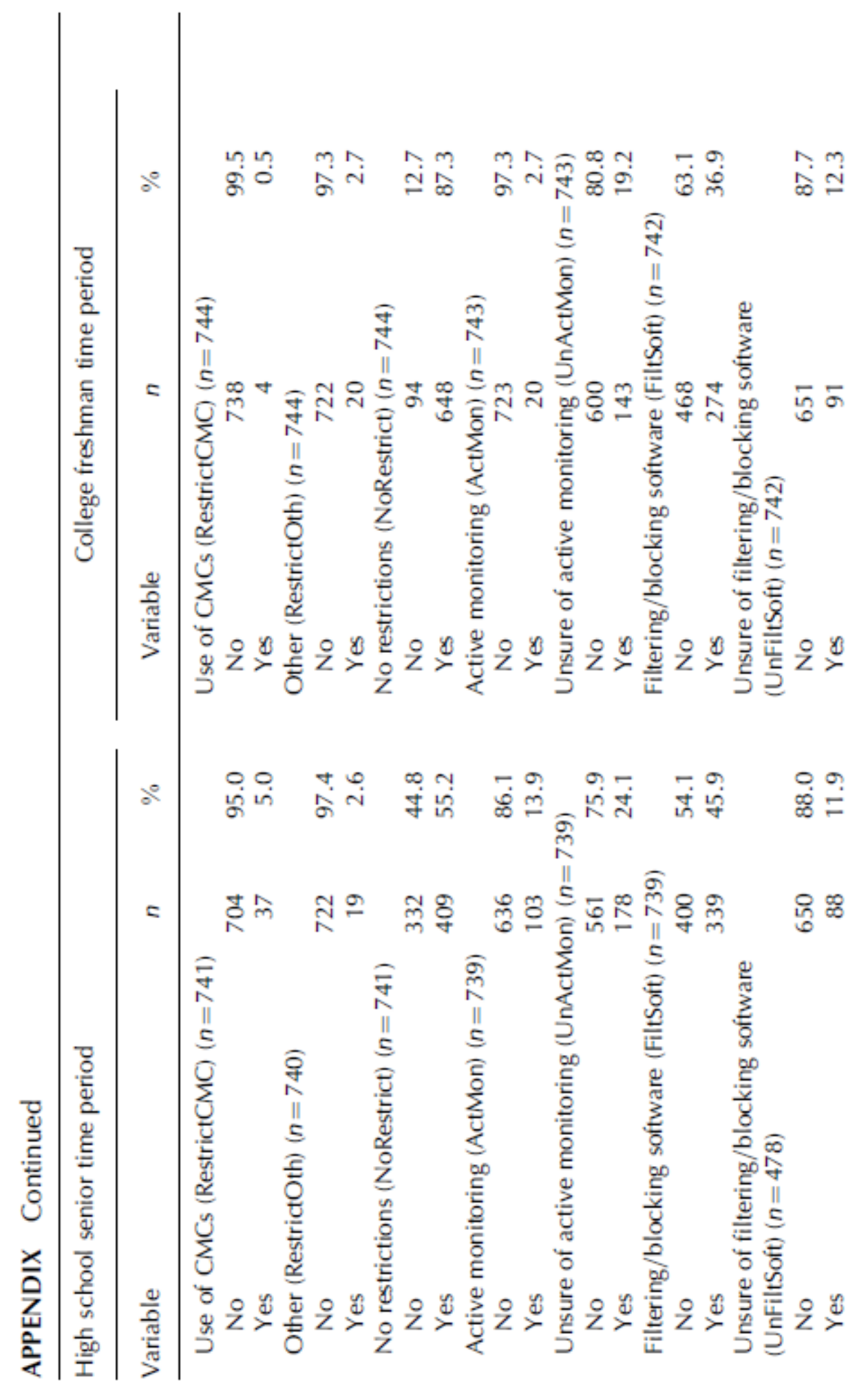




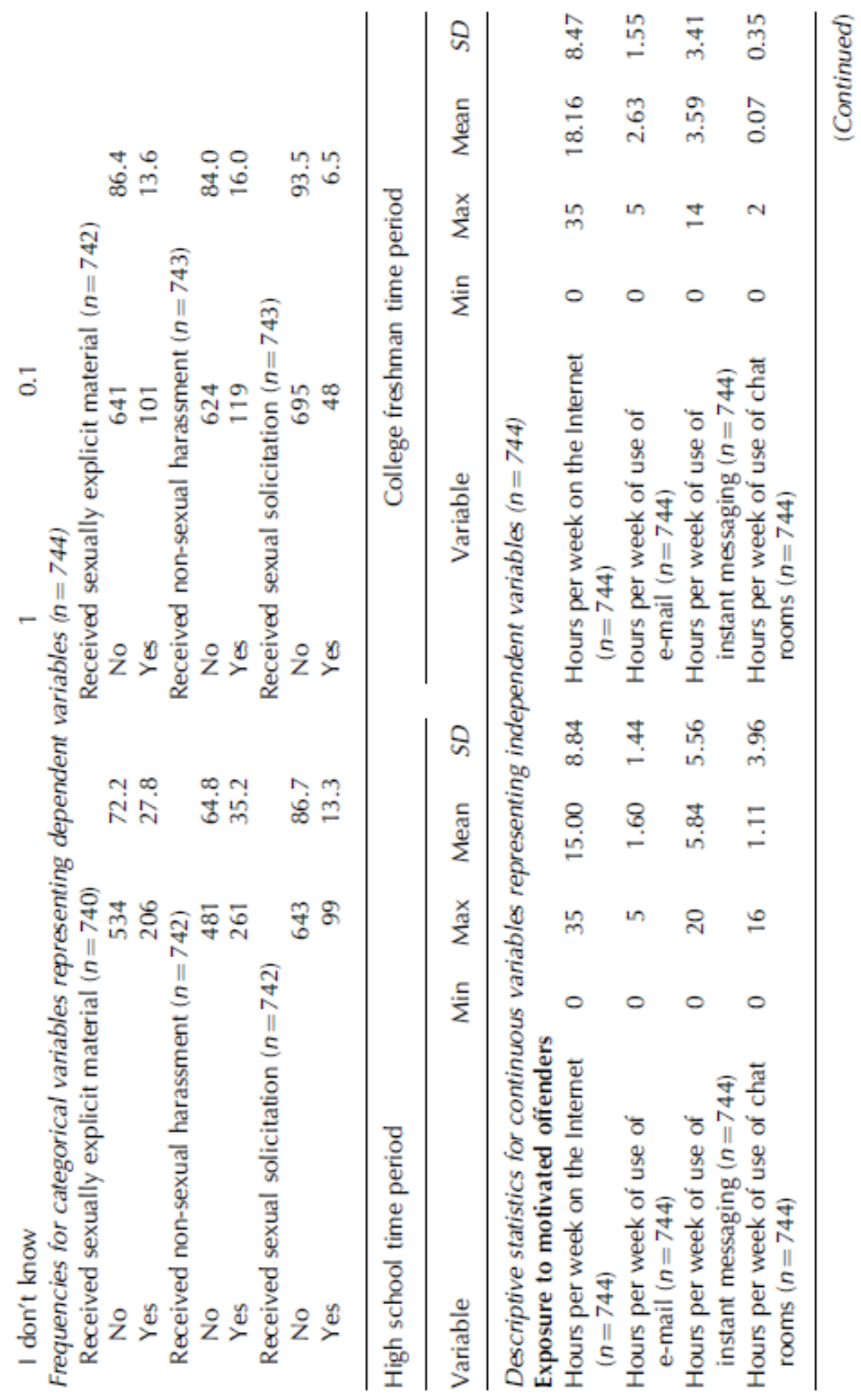




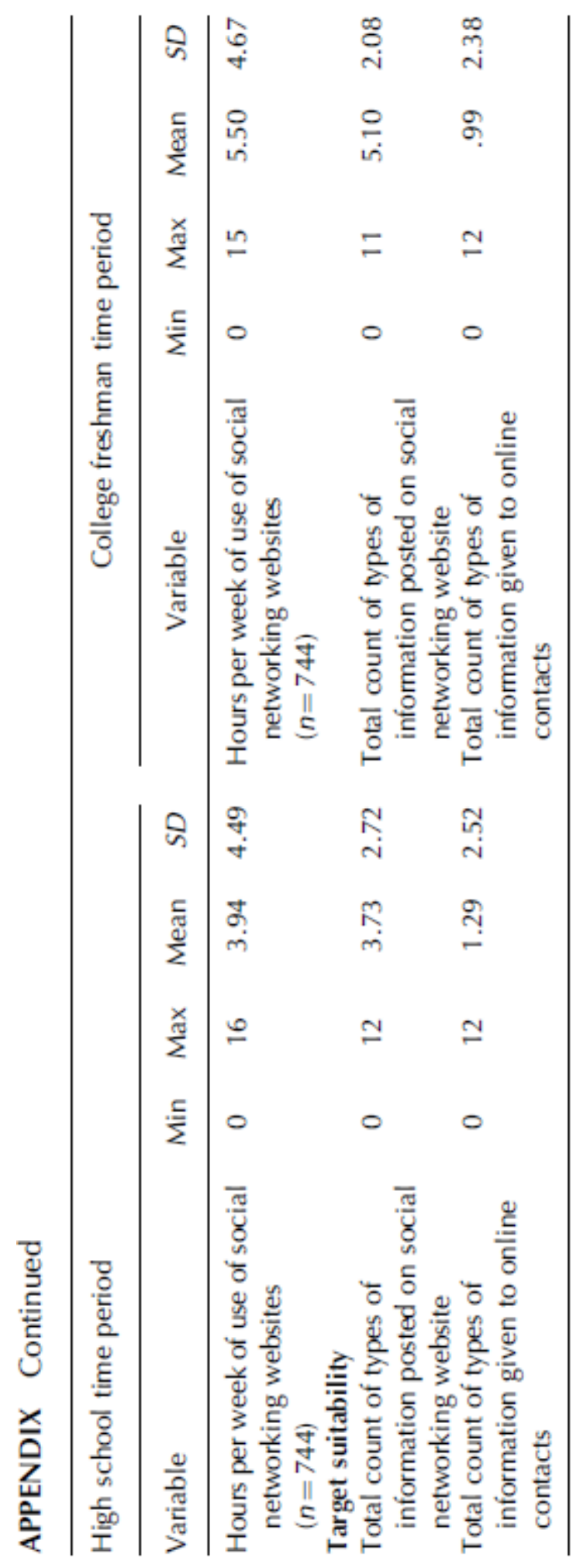




\section{NOTES}

${ }^{1}$ Z-scores were run to assess the logistic parameters between the two time periods. No significant differences between the two time periods for each dependent variables were found.

${ }^{2}$ First, variables measuring the theoretical construct of exposure to motivated offenders were inserted in the models to examine their effects on the dependent variables. The next model considered the addition of the effects of the independent variables measuring the theoretical construct of target suitability, while also including retained variables measuring exposure to motivated offenders. Third, lack of capable guardianship variables were assessed, in addition to the effects of the other two sets of retained independent variables. Finally, full models were constructed with the addition of the control variables, while also including the retained measures of the three theoretical constructs.

${ }^{\star} p<.05 ;{ }^{* \star} p<.01 ;{ }^{* \star *} p<.001$

${ }^{\star} p<.05 ;{ }^{* \star} p<.01 ;{ }^{* \star *} p<.001$.

${ }^{\star} p<.05 ;{ }^{* \star} p<.01 ;{ }^{\star \star \star} p<.001$.

\section{REFERENCES}

Adler, P. and P. Adler. 2006. "The Deviance Society." Deviant Behavior 27:129-149.

Agresti, A. and B. Finlay. 1997. Statistical Methods for the Social Sciences. Upper Saddle River, NJ: Prentice Hall.

Arnold, R., C. Keane, and S. Baron. 2005. "Assessing Risk of Victimization Through Epidemiological Concepts: An Alternative Analytic Strategy Applied to Routine Activities Theory." Canadian Review of Sociology and Anthropology 423:345-364.

Bendel, R. and A. Afifi. 1977. "Comparison of Stopping Rules in Forward Stepwise Regression." Journal of the American Statistical Association 72:46-53.

Brantingham, P. and P. Brantingham. 1981. Environmental Criminology. Beverly Hills, CA: Sage.

Cohen, L. and D. Cantor. 1980. "The Determinants of Larceny: An Empirical and Theoretical Study." Journal of Research in Crime and Delinquency 17:140-159.

Cohen, L. and M. Felson. 1979. "Social Change and Crime Rate Trends: A Routine Activity Approach." American Sociological Review 44:588-608. 


\section{- 1981. "Modeling Crime Trends: A Criminal Opportunity Perspective." Journal of Research in Crime and Delinquency 18:138-164.}

Felson, M. 1986. "Linking Criminal Choices, Routine Activities, Informal Social Control, and Criminal Outcomes." Pp. 119-128. In The Reasoning Criminal, edited by D. Cornish and R. Clarke. New York: Springer-Verlag.

Fleming, M., S. Greentree., D. Cocotti-Muller, K. Elias, and S. Morrison. 2006. "Safety in Cyberspace: Adolescents' Safety and Exposure Online." Youth and Society 38:135-154.

Gaetz, S. 2004. "Safe Streets for Whom? Homeless Youth, Social Exclusion, and Criminal Victimization." Canadian Journal of Criminology and Criminal Justice 46:423-455.

Garofalo, J. and D. Clark. 1992. "Guardianship and Residential Burglary." Justice Quarterly 9(3):443-463.

Hawley, A. 1950. Human Ecology. New York: The Ronald Press Company.

Hindelang, M., M. Gottfredson, and J. Garofalo. 1978. Victims of Personal Crime: An Empirical Foundation for a Theory of Personal Victimization. Cambridge, MA: Ballinger Publishing Company.

Horney, J., D. Osgood, and I. Marshall. 1995. "Criminal Careers in the Short-Term: Intra-Individual Variability in Crime and Its Relation to Local Life Circumstances." American Sociological Review 60:655-673.

Izenberg, N. and D. Lieberman. 1998. "The Web, Communication Trends, and Children's Health: How the Children Use the Web." Clinical Pediatrics 37:335-340.

Jackson, A., K. Gililand, and L. Veneziano. 2006. "Routine Activity Theory and Sexual Deviance among Male College Students." Journal of Family Violence 21(7):449-460.

Kendall, V. 1998. "The Lost Child: Congress's Inability to Protect our Teenagers." Northwestern University Law Review 92:1307-1315.

LaGrange, T. 1999. "The Impact of Neighborhoods, Schools, and Malls on the Spatial Distribution of Property Damage." Journal of Research in Crime and Delinquency 36:393-422.

Lwin, M., A. Stanaland, and A. Miyazaki. 2008. "Protecting Children's Privacy Online: How Parental Mediation Strategies Affect Website Safeguard Effectiveness." Journal of Retailing 84:205-217. 
Marcum, C. D. forthcoming. "Adolescent Online Victimization: Comparing Genders Through a Test of Routine Activities Theory." Journal of Criminal Justice and Popular Culture.

Meier, R. and T. Miethe. 1993. "Understanding Theories of Criminal Victimization." Pp. 459-499. In Crime and Justice: An Annual Review of Research, edited by M. Tonry. Chicago: University of Chicago Press.

Mernard, S. 2002. Applied Logistic Regression Analysis (2nd ed.). Thousand Oaks, CA: Sage Publications.

Messner, S. and K. Tardiff. 1985. "The Social Ecology of Urban Homicide: An Application of the Routine Activities Approach." Criminology 23(2):241-267.

Mitchell, K., D. Finkelhor, and J. Wolak. 2003. "The Exposure of Youth to Unwanted Sexual Material on the Internet: A National Survey of Risk, Impact and Prevention." Youth and Society 34: 3300-3358.

- 2007. "Youth Internet Users at Risk for the More Serious Online Sexual Solicitations." American Journal of Preventative Medicine 32:532-537.

Mustaine, E. and R. Tewksbury. 1999. "A Routine Activities Theory Explanation for Women's Stalking Victimization." Violence Against Women 5:43-62.

Activities Analysis." Criminal Justice Review 27(1):89-123.

Nie, N. and L. Erbring. 2000. Internet and Society: A Preliminary Report. Stanford: Stanford Institute for the Quantitative Study of Society.

O'Connell, R., C. Barrow, and S. Sange. 2002. "Young Peoples Use of Chat Rooms: Implications for Policy Strategies and Programs of Education." Available at http://www.uclan.ac.uk/host/cru/publications. htm (accessed November 1, 2005).

Pratt, T. and Cullen, F. 2005. "Assessing Macro-Level Predictors and Theories of Crime: A Meta-Analysis." Pp. 373-450. In Crime and Justice: A Review of Research, edited by Michael Tonry. Chicago: University Press.

Quayle, E. and M. Taylor. 2003. "Model of Problematic Internet Use in People with a Sexual Interest in Children." CyberPsychology and Behavior 6:93-106.

Roncek, D. and R. Bell. 1981. "Bars, Blocks, and Crimes." Journal of Environmental Systems 11:35-47. 
Roncek, D. and P. Maier. 1991. "Bars, Blocks, and Crimes Revisited: Linking the Theory of Routine Activities to the Empiricism of 'Hot Spots." " Criminology 29:725-753.

Sanger, D., A. Long, M. Ritzman, K. Stofer, and C. Davis. 2004. "Opinions of Female Juvenile Delinquents about Their Interactions in Chat Rooms." Journal of Correctional Education 55:120-131.

Schreck, C. and B. Fisher. 2004. "Specifying the Influence of the Family and Peers on Violent and Victimization." Journal of Interpersonal Violence 19:1021-1041.

Schwartz, M., W. DeKeseredy, D. Tait, and S. Alvi. 2001. "Male Peer Support and a Feminist Routine Activities Theory: Understanding Sexual Assault on the College Campus." Justice Quarterly 18(3):623-649.

Schwartz, M. and V. Pitts. 1995. "Exploring a Feminist Routine Activities Approach to Explaining Sexual Assault." Justice Quarterly 12:9-31.

Spano, R. and S. Nagy. 2005. "Social Guardianship and Social Isolation: An Application and Extension of Lifestyle=Routine Activities Theory to Rural Adolescents." Rural Sociology 70:414-437.

Tarbox, K. 2000. Katie.com. New York: Penguin Group.

Tewksbury, R. and E. Mustaine. 2000. "Routine Activities and Vandalism: A Theoretical and Empirical Study." Journal of Crime and Justice 23:81-110.

Tseloni, A., K. Wittebrood, G. Farrell, and K. Pease. 2004. "Burglary Victimization in England and Wales, the United States and the Netherlands." The British Journal of Criminology 44(1):66-91.

United States Department of Commerce. 2002. Computer and Internet Usage by Age and Disability Status: 2002. Washington, DC: United States Department of Commerce. Available at http://www.census. gov/hhes/www/disability/sipp/disab02/ds02f6.pdf (accessed March 1, 2007).

Wang, J. 2002. "Bank Robberies by an Asian Gang: An Assessment of the Routine Activities Theory." International Journal of Offender Therapy and Comparative Criminology 46:555-568.

Wolak, J., K. Mitchell, and D. Finkelhor. 2002. "Close Online Relationships in a National Sample of Adolescents." Adolescence 37: 441-455.

2003. "Escaping or Connecting? Characteristics of Youth Who Form Close Online Relationships." Journal of Adolescent Health 26:105-119. 
_. 2004. "Internet-Initiated Sex Crimes Against Minors: Implications for Prevention Based on Findings from a National Study." Journal of Adolescent Health 35:11-20.

2006. Online Victimization of Children: Five Years Later.

Washington, DC: National Center for Missing and Exploited Children.

2007. "Unwanted and Wanted Exposure to Online Pornography in a National Sample of Youth Internet Users." Pediatrics 119:

247-257.

Ybarra, M., K. Mitchell, D. Finkelhor, and J. Wolak. 2007. "Internet Prevention Messages: Targeting the Right Online Behaviors." Archives of Pediatric and Adolescent Medicine 161:138-145. 